\title{
Papp László utazása (1946-2021): ez mind ő volt egykoron
}

\author{
DARVAS BÉLA \\ Magyar Ökotoxikológiai Társaság, H-1022 Budapest, Herman Ottó út 15., Magyarország \\ E-mail:bdarvas@bdarvas.hu
}

\begin{abstract}
Összefoglalás - A Magyar Természettudományi Múzeum légygyűjteménye 1971 végén - mikor Papp László a munkáját kezdte - 330 ezer példányt számlált. 2010-ben, nyugdíjba vonulásakor ez a szám elérte az egymilliót. 400 ezer példánnyal ő maga gyarapította a gyüjteményt. 27 országban járt és többségükben gyüjtött is. Tevékenysége legértékesebb részének a gyüjtemény építését tartotta. Tudományos munkáiban öt családcsoport nevet állított fel, 97 új nemzetséget és 742 új légyfajt írt le (a halála után további kilenc jelenik még meg). Magyarország légyfaunájából több mint kétezer, addig ismeretlen fajt mutatott ki. Szakcikkei többnyire Magyarországon, de angolul jelentek meg. A Magyar Tudományos Művek Tára szerint négyszáz fölötti írására eddig több mint 2500 független idézetet kapott. Öt ábrával és két melléklettel: (1) Papp László szakirodalmi jegyzéke (válogatta Darvas Béla) és (2) Papp László által leírt család-, génusz- és fajcsoport nevek listája.
\end{abstract}

Kulcsszavak - Diptera, Magyar Természettudományi Múzeum, Magyar Tudományos Akedémia, Manual of Palaearctic Diptera, taxonómia

\section{IDŐUTAZÁS}

Nem szeretek a múlttal szembesülni. Megvisel. Elmúlt - ez az élet rendje -, akkor feledjük; csakhogy nem tudok. Laci, aki Jenőként született Aranyosgadányban egy parasztcsalád első gyermekeként, szintén nem szeretett a múltba merülni. „Tessék engem most megbecsülni, az utókor nem érdekel” - mondta egyszer kifakadva, és ezt történetesen én is mondhattam volna. Pedig én nem a Magyar Természettudományi Múzeumban (MTM) dolgoztam, mint ő, ahol a fizetések lehangolóan alacsonyak voltak. Ide - ebbe a Baross utcai komor épületbe - az jött, aki a gyüjtemény megszállottja volt. A rendszerváltás előtt többet kerestem egy Magyar Tudományos Akadémia (MTA) kutatóintézetben dolgozva fömunkatársként, mint ő kurátorként (DA RVAs 2003a; 2003b; 2003c). Persze az én fizetésem is hússzor lett volna több, ha történetesen norvégnak születek. 


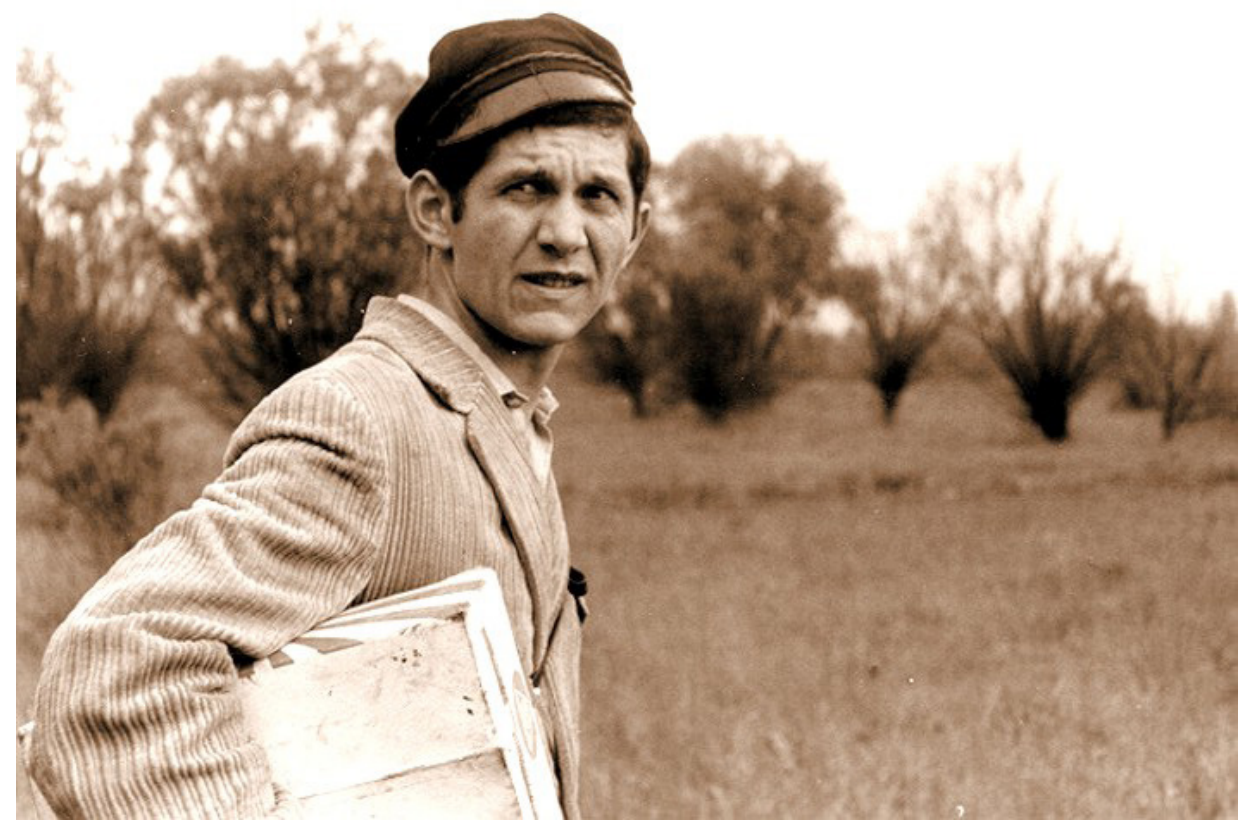

1. ábra. Papp László 1973-ban

(fotó: a Papp család tulajdona, forrás: http://www.bdarvas.hu/portre/idn3503)

Kezdjük az elején, elkerülve a formális pátoszt. Ez utóbbira semmilyen indíttatásom nincs, mint ahogy annak sem lett volna, akiről írok. Tessék nekem megbocsátani, hogy a tények mögül néha kikandikálok. Abszolút jellemző a korombéliekre, akiknek emlékei gyűltek, ráadásul akiről írok, attól magamban hordozom személyiségének repeszeit. Van olyan, ahol nehezen tudom elkülöníteni azt, hogy mi az enyém, és mi az övé. Persze sok minden elválaszt tőle, de most nem erre fogok hangolódni. Én azt feltételezem, hogy a róla alkotott képem élesebb, mint az átlagos, hiszen sok mindenről beszélhettünk közel 45 évnyi ismeretségünk alatt. Ez a visszaemlékezés a maga korlátaival nem szólhat mindenről. Nem szólhatok kellő mélységben a Diptera gyűjtemény múltjáról (LENGYEL 2012), az általam ismert munkatársairól, Mihályi Ferencről és Delyné Draskovits Ágnesről sem.

A Nemzeti Múzeum hátsó lépcsőin értem el azt az emeleti termet, ahol először láttam meg a Rovartani Társaság akkori titkárát, Papp Lászlót. Bajuszos, szigorú embernek tünt. Olyannak, aki habozás nélkül kijavít. Évekkel később, 1976-ban, vöröshagymából nevelt legyekkel kopogtattam be a Diptera gyüjteménybe. Papp doktor azt kérdezte, hogy mit tudok a kétszárnyúakról. Mihályi Ferenc könyvét olvastam - feleltem, így utólag is túlzón. Rám nézett és 
azt mondta: „Az jó, pláne, ha tudja is alkalmazni, ami benne található. A kollega meg lenne lepődve milyen kevesen képesek dipterológiában - akár családokra is hitelesen - határozni" (DARvas 2003a). Aztán lekerült róla a bajusz, és úgy négy év múlva már nem magázott. Nem kis megnyugvással láttam később, hogy miként játssza el ezt mindenkivel. Először akkor láttam zavarba jönni, mikor megkérdeztem, hogy mi történt a bajszával? Nem válaszolt, a fejét kissé félre fordította és mosolygott.

A pécsi Nagy Lajos Gimnáziumban 1965-ben érettségizett, majd az Eötvös Lóránd Tudományegyetem (ELTE) Természettudományi Karának (TTK) biológus szakán tanult (PAPP 2021a). Nem volt katona, mégis ennek az állapotnak minden vonását viselte. Biológus diplomáját 1970-ben kapta meg és azonnal az MTM-ben helyezkedett el (1. ábra).

$\mathrm{Az}$ egyetemi évei alatt Balogh János bíztatására kezdett el legyekkel foglalkozni. A Diptera gyüjteményt Mihályi Ferenc vezette akkortájt (2. ábra). Bár mentora Balogh János volt, de tudományos gondolkodására Jermy Tibor és Juhász-Nagy Pál voltak a legnagyobb hatással.

\section{EZ MIND Ő VOLT EGYKORON}

Az MTM-ben Gozmány Lászlótól és Soós Árpádtól tanulta a legtöbbet - mondta nekem egyszer. Soós Árpád mellett szerkesztője volt a Catalogue of Palaearctic Diptera 13 részes sorozatának (lásd 1. melléklet), amely közel ötezres oldalszámával a legnagyobb terjedelmủ általa végzett szerkesztői munka volt. A katalógus afféle leltár; milyen fajokat, ki, hol publikált, és hol található a típuspéldány. Ez a komoly odafigyelést igénylő aktivitás erősen a rabszolgamunkára emlékeztet. A 13 kötet 58 szerzővel készült, és közülük 17 fejezet szerzője Papp László volt. 1984-1993 között megjelent kötetek közül az utolsó két kötetet már egyedül szerkesztette; Soós Ârpád 1991-ben meghalt. Szinte alig, hogy a katalógus munkái befejeződtek, kezdte el velem a Contributions to a Manual of Palaearctic Diptera köteteit (lásd 1. melléklet). Ez 1997 és 2000 között közel háromezer oldalon jelent meg. 84 nemzetközileg jegyzett szerzővel dolgoztunk - a levelezés óriási volt -, és ebben a munkában már nem mechanikusan ismétlődő szöveget szerepeltettünk, hanem az angolságot tekintve is komoly próbatételt jelentő egyedi szövegeket. Az első kötet inkább az én munkám volt, míg a második, a harmadik és Appendix kötet az övé. Oldalszám tekintetében én voltam a kötetekben a legtöbbet publikáló szerző. Ezt követte 2001-ben az általa szerkesztett Checklist of the Diptera of Hungary (lásd 1. melléklet). A Magyar Tudományos Müvek Tára (MTMT) szerint Papp László teljesítményének csúcsévei voltak ezek. Dacára annak, hogy szerkesztett munkáit fel sem tüntette; 18-ból csak hetet találunk meg itt. 
Papp László 2004-ben kapott, és föként a kézikönyvéért Széchenyidíjat (2. ábra). Eredetileg engem terjesztettek fel vele együtt; aztán másként lett. „Akadémikus az lesz, aki hallgat” - ezt éppen ő mondta nekem, és a saját példámon ezt meg is tapasztaltam ezt (BoDoKy és DARVAs 2008). Hallgatni? $\mathrm{Na}$, azt nem tudok. Mondjuk Laci sem, de benne a fékek hatékonyabban működtek, mint nálam. Ô rezzenéstelenül hallgatott végig - elsötétülő tekintettel - abszurd tartalmakat, és csak akkor robbant fel, amikor a kagylót letette. Sokszor voltam ennek tanúja, hiszen kiszaladt hozzám lecsillapodni oda, ahol péntekenként évekig dolgoztam. Érteni véltem, amit ennek a múzeumnak a tehetséges fiataljai, Földvári Mihály és Szűcs Tamás ebéd közben meséltek egymásnak. Az MTM-ben kapott bérből megélni és családot alapítani nem lehetett. A munka szinte ingyenes volt, a teljesítményigény viszont óriási, miközben a szupraindividuális biológia pályázati támogatása a béka ülepe alatt tanyázott.

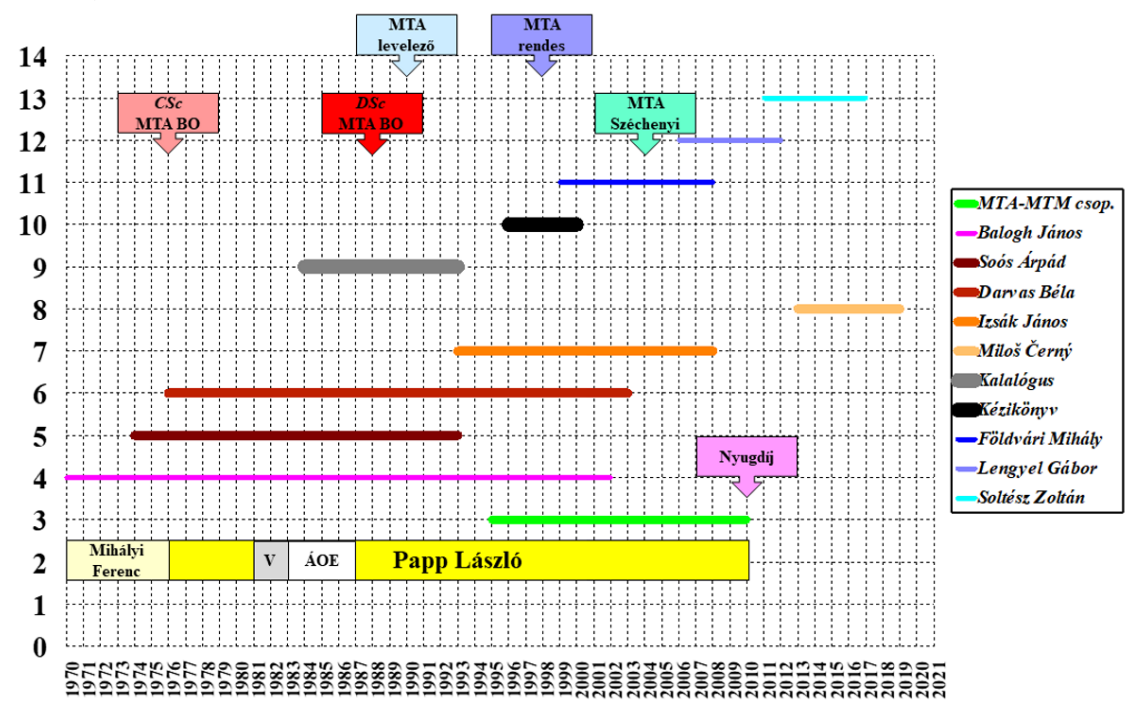

2. ábra. Papp László szakmai életútjának vázlata. 2: a pálya állomásai - Mihályi Ferenc a Diptera Gyűjtemény kurrátor elődje, V - tanító a Vecsési Általános Iskolában, ÁOE - egyetemi oktató az Állatorvostudományi Egyetem, Általános Állattani és Parazitológiai Tanszékén (tanszékvezető: Kassai Tibor), élénk sárgával Papp László kurátori megbízatása; 3-13 meghatározó hazai munkakapcsolatai; címkék: $C S c, D S c$, az MTA levelező, az MTA rendes tagja tudományos fokozatok és rangok megszerzése, az MTA Széchenyi díja, a nyugdíj kezdete. (szerkesztette: Darvas Béla)

Ez az időszak az, amikor az infraindividuális és a szupraindividuális biológia megütköztek egymással. Ez leginkább az akadémikus-választás időszakában csúcsosodott ki, amikor Papp László telefonja is izzott. Mi megválasztjuk a ti gyengéiteket, ha ti a mieinket - foglalhatnám össze az egyezkedés lényegét. Ma 
is döbbenten nézem, az így megválasztott akadémikus urakat. A homokvárakat bizony szétfújja az idő szele. Papp László talán helyettük is gürcölt olyan elkeseredetten, bár valamennyien versenyt futunk az idővel, akiknek a Teremtő lámpást adott. Balogh János halála után a harc eldőlt, a zöld akadémikusok veszítettek.

A kézikönyv sikerét vártuk, de az nem következett be. A könyvterjesztés nem volt kellőképpen átgondolva. Ehhez a munkafázishoz nem volt közöm. Végül a Classey (Oxford, Egyesült Királyság) nemzetközileg jegyzett antikvárius vette át bizományban a méregdrága sorozatot, hogy aztán ott eltűnjenek a könyvek, a pénzügyi haszonnal együtt. Utóbbi senkit nem foglalkoztatott. Mint szerkesztő, hat évig dolgoztam tehát ingyen, a saját karrieremet is félresöpörve. Ma sem tudom, hová került a könyvek haszna. Tény, hogy ezzel a szép könyvritkasággal a könyvpiacon és az interneten antikvárius kereskedés folyik. A megjelenés után 15 évvel próbálkoztam azzal, hogy a könyv elektronikus (pdf) változata kerüljön a netre, vagyis, ha már nem vált üzletté a szerkesztőknek sem, legalább a munka szabad terjesztését oldjuk meg. A Pars Kft. (Peregovits László) segítségével teszünk most erre egy kísérletet.

Laci egyetlen munkahelyen élte az életét (3. ábra). Azt hiszem, mindenféle értelemben monogám volt. 1981-1982-ben önérzetében sértetten elment ugyan Vecsésre általános iskolai tanítónak, de 1982-1986-ban már, Kassai Tibor hívására az Állatorvostudományi Egyetem, Általános Állattani és Parazitológiai Tanszékén dolgozott. A tanítás megújította, lendülete és lelkesültsége visszatért. Mondanom sem kell, hogy bár öt évig nem a múzeum volt a munkahelye, a muzeológusi munkáját nem adta fel. Róka fogta csuka. A feladata cipelte őt magával. 1986-ban együtt szerveztük az első Dipterológiai Világkonferenciát, és indítottunk el valamit, ami ma is működik. Én 1983-ban szerveztem már nemzetközi konferenciát, így logikusan esett rám a választása. Az egyik dolog hozza a másikat. 2010. december 29. után lett nyugdíjas. Önként ment el, mások miatt sértetten, de a gyüjteményi munkáját ekkor sem adta fel, $\mathrm{s}$ az egyik legjelentősebb vállalkozásába (Agromyzidae) ekkor kezdett.

Az MTM légygyüjteménye 1971 végén - mikor Papp László a munkáját kezdte - 330 ezer példányt számlált. 2010-ben, nyugdíjba vonulásakor ez a szám elérte az egymilliót. 400 ezer példánnyal ő maga gyarapította a gyűjteményt. Több gyűjtőexpedíciót vezetett: Afganisztán (1974), India (1989), Tajvan (2000), Thaiföld (2004), és Vietnam (2009). Tevékenysége legértékesebb részének a gyüjtemény építését tartotta. Tudományos munkáiban öt családcsoport-nevet állított fel, 97 új génuszt és 742 új légyfajt írt le (PAPP 2021b) (halála után még további kilenc jelenik meg, lásd 2. melléklet). Fajainak egy jelentős részét dipterológus elődjeinek (Kertész Kálmán, Soós Árpád, Mihályi Ferenc), kollégáinak (Szelényi Gusztáv, Gozmány László, Mahunka Sándor, Endrődi-Younga Sebestyén, Demeter András, Peregovits László, Ronkay László), továbbá tanítványainak (Földvári Mihály, Szappanos Bertalan) ajánlotta. Különösen sok faja őrzi egykori igazgatója, Kaszab Zoltán (hét faj) és tanára, 
Balogh János (négy faj) emlékét. Magyarország légyfaunájához több mint kétezer - addig itt nem jegyzett - új fajt mutatott ki és írt le.

Izsák János matematikussal sok cikket közöltek a kvantitatív ökológia területén. A légyfajok többsége szerintük ritka (PAPP 2021a). A ritkaság, a jó és rossz $f a j$, a szárnyatlanság kitartóan foglalkoztatták.

Négy angol kötetet írt (1900 körüli oldal) Miloš Černý-vel, és már nyugdíjasként, az aknázólegyekről. A könyvek Magyarországon jelentek meg és a Pars adta ki ezeket. Erre a munkára valamikor én beszéltem rá. Mindkettőnknek világossá vált, hogy a terület szakértője (Kenneth A. Spencer) a meghatározásra olyan rajzokat kínál, amelyek preparátumait az előkészítés során szinte felismerhetetlenre maratott szét lúggal. Az ivarszerv preparálásra a tejsav alkalmasabb.

Hat magyar nyelvü könyvet írt. Ezeket a Magyarország Állatvilága sorozatban az Akadémiai Kiadó adta ki.

Munkájaként az Magyar Tudományos Mủvek Tára (MTMT) adatbázisa 84 angol nyelvủ könyvrészletet sorol fel, ezek többsége hazánkban jelent meg, és 32 magyar nyelvü könyvrészletet. 18 angol nyelvü szerkesztett könyvet tudhat magáénak (ez munkásságának legterjedelmesebb része), valamennyi magyar kiadású (Akadémiai Kiadó, Science Herald, Pars). Egy magyar nyelvű szerkesztett könyve van: a Zootaxonómia címü, amit az egyetemi oktatás használ.

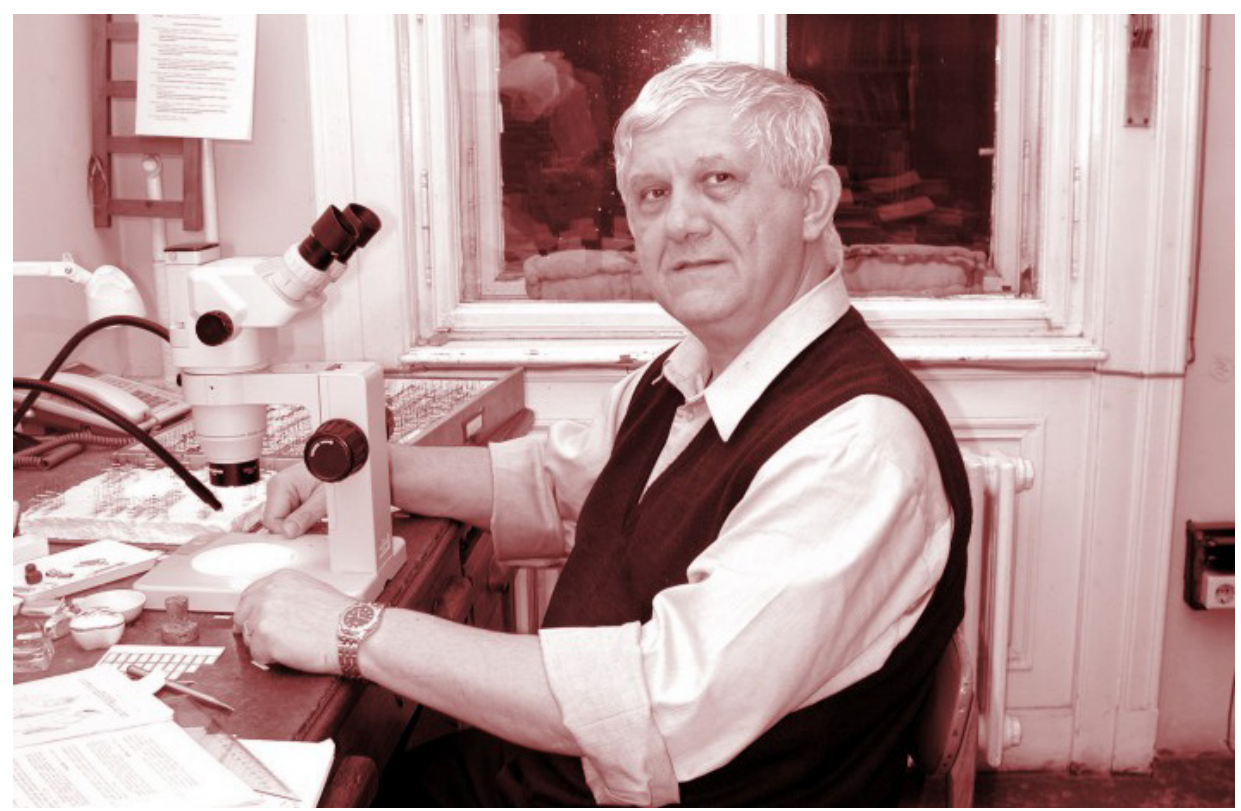

3. ábra. Papp László 2003-ban az MTM Léggyűjteményében levő munkaasztalánál. (fotó: Darvas Béla, forrás: http://www.bdarvas.hu/portre/idn3503) 


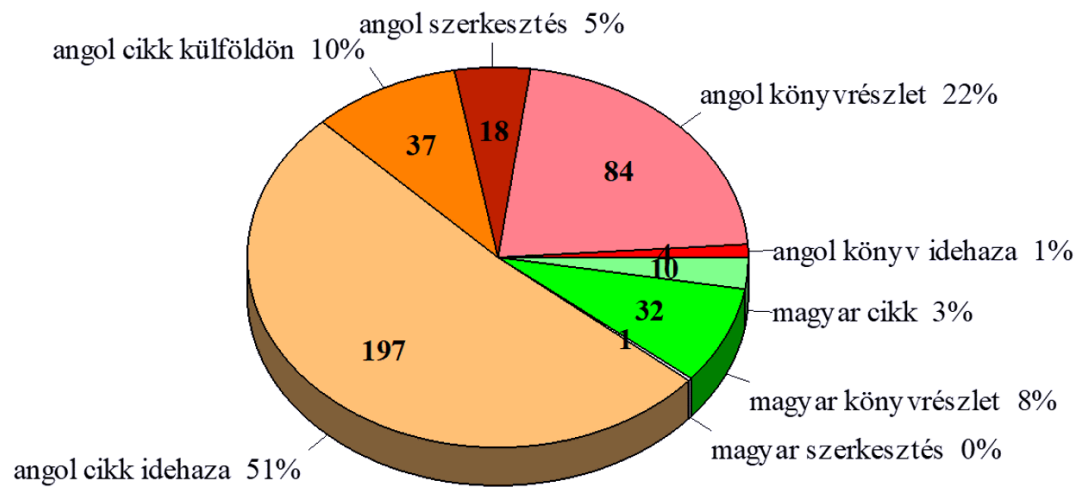

4. ábra. Papp László publikációinak elemzése, készült a Magyar Tudományos Művek Tára és Papp László feljegyzései alapján: tudományos minősítéshez írt anyagok, angol nyelvű könyvek, magyar nyelvü könyvek, angol nyelvü szerkesztett könyvek, angol nyelvű szakcikkek, magyar nyelvü szakcikkek. (a listát válogatta és szerkesztette: Darvas Béla)

37 külföldön megjelent angol nyelvü cikket írt, amelyben figyelemreméltó társszerzője Izsák János. 197 angol nyelvủ cikke (PAPP 2021c) hazai folyóiratokban jelent meg (pl. Acta Zoologica Academiae Scientiarim Hungaricae, Folia entomologica hungarica.). Közülük egyet azért kiemelek, amit az 1975-ös megjelenés után több évtizeddel a kezembe nyomott, hogy ismerem-e? Arról szólt, hogy a trágyából elképesztő mennyiségű légynyű nevelhető, s azt lehetne esetleg takarmányozási célra használni. Ma gyakran pedzegetik a rovarproteinek felhasználását, amivel kapcsolatban az erre rá nem szoruló Európai Unió országai fanyalognak. Az MTMT adatbázisa csupán tíz magyar nyelvü cikket tartalmaz (4. ábra). A dipterológia nem az a tudományterület (kivéve a vérszívókat), aminek támogatottsága és pályázati lehetőségei jók. Nem véletlen, hogy a világ természettudományi gyüjteményeit sorban zárták be. 1994-ben a zootaxonómia bizonytalan jövője nem véletlenül foglalkoztatta Papp Lászlót. A muzeológusi szakma minden értelemben teret veszített.

Munkái tehát többnyire Magyarországon, de nem magyarul jelentek meg. Az MTMT szerint négyszáz fölötti írására eddig több, mint 2500 független idézést kapott, s ebben az új fajok leírása vezető helyen szerepel.

1982-2014 között oktatott az Állatorvostudományi Egyetemen, az ELTE TTK-n, a Szegedi és Debreceni Tudományegyetemen. A Debreceni Egyetem Juhász-Nagy Pál Doktori Iskola törzstag emeritusa volt, az ELTE Környezettudományi Doktori Iskola oktatója. Három $\mathrm{PhD}$-hallgató végzett nála: Földvári Mihály (2004), Lengyel Gábor (2012) és Soltész Zoltán (2019). Egyikük sem maradt a gyüjteményben, sőt Lengyel Gábor a biológusi pályán sem; Földvári Mihály az országot hagyta el, ma Svédországban él. 
A Royal Entomological Society tagja volt. Utoljára 2019. augusztusában láttam konferencián az MTA épületében. Csípőszúnyogokról és kullancsokról volt szó, ő hamar otthagyta a pulpitust, a többiek észre sem vették, hogy más helyén ülnek. Most látom csak, hogy nem említettem pár embert, akivel a légygyüjteményben többször találkoztam: Dévai Györgyöt (Debreceni Egyetem), Mayer Józsefet (Pécsi Tudományegyetem), Szappanos Albert (állatorvos, grafikus) és Tóth Sándort (Zirci Múzeum). Mondjuk, Tóth Sándornak a csípőszúnyogok miatt ott lett volna a helye azon a pulpituson.

Papp László nem vett részt már a MTM elköltözésének megtervezésében. Sőt, igyekezett ezt az ügyet magától távol tartani. Az átgondolatlan költözködési terveket (akárcsak a muzeológusok többsége, vagy Matskási István) azonban ellenezte, mivel ezek a sérülékeny gyüjtemény részbeni pusztulásához vezetnek.

Ennyire futotta most nekünk. Elérkeztem a lehetőségem végére, ahol Abe Kobo története köszön vissza ránk. Lacinak is az egyik kedvenc könyve volt. Dzümpei a dűnék között egy futrinkát kergetve esik végül saját sorsának csapdájába. Eltérő az út hossza, amiben megértjük, hogy „A büntetés veszélye nélkül nincs öröm a szökésben...", sőt az érdemi még ezen is túl van, a személyes hasznosulásunkban. Ez lehet a család, ahová Laci végül megtért. Aranyosgadányban 2021. április 9-én temették.

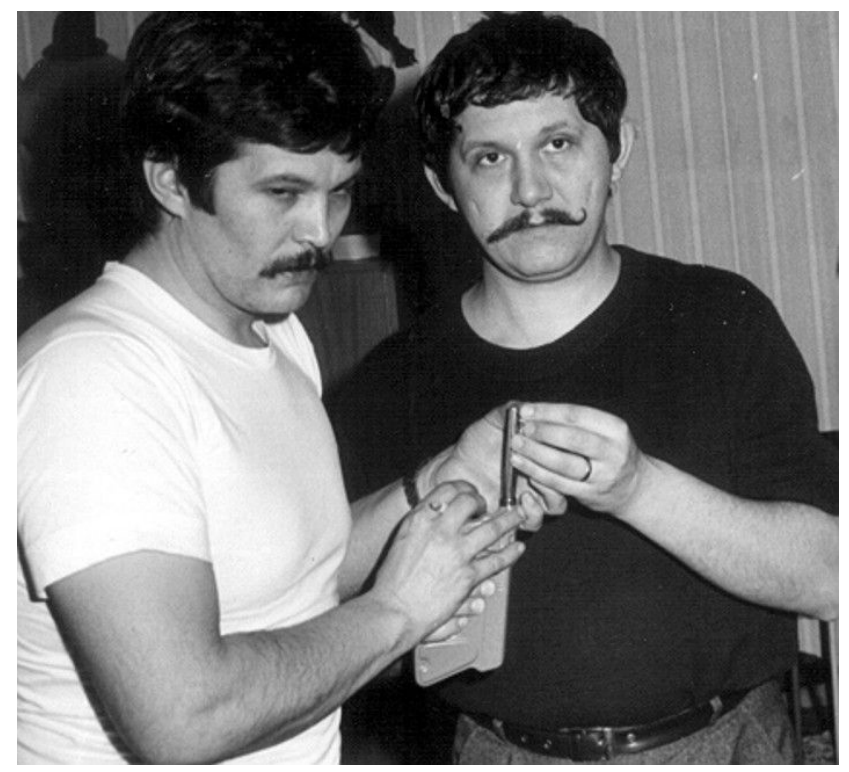

5. ábra. Papp (Jenő) László és testvére Papp Lajos szívsebész a hetvenes évek végén. (fotó: a Papp-család tulajdona, forrás: http://bdarvas.hu/main.php?id=6116) 
Köszönetnyilvánítás - Köszönöm Papp Jánosnak, hogy édesapja saját maga által készített önéletrajzát, faj- és szakirodalmi listáját megküldte. Ezt a saját honlapomon közzéteszem, hogy mint forrást, a jövőben bárki használhassa. Köszönet Székács Andrásnak a kéziraton végzett munkájáért.

\section{HIVATKOZÁSOK}

Bodoky T. és Darvas B. 2008: Akadémikus az lesz, aki hallgat. - Index, 2018. március 5.

(https://index.hu/tudomany/darvas2041/) (utolsó látogatás: 2021. október 27.)

Darvas B. 2021: Papp (Jenő) László (1946-2021) - Darvas Béla személyes búcsúja (https://www.facebook.com/photo/?fbid=2688694101369811\&set=a.1667876520118246) (utolsó látgatás: 2021. október 27.

DARVAs B. és PAPP L. 2003a: Papp Lászlóval, amiről még eddig nem beszéltünk. I. Aranyosgadány felöl, félúton. - e-Világ, 2 (2): 25-31.

(http://www.bdarvas.hu/portre/idn3503) (utolsó látogatás: 2021. október 27.)

Darvas B. és Papp L. 2003b: Papp Lászlóval, amiról még eddig nem beszéltünk. II. Megszámlálható-e az ismeretlen? - e-Világ, 2 (3): 35-38.

(http://www.bdarvas.hu/portre/idn3503) (utolsó látogatás: 2021. október 27.)

Darvas B. és Papp L. 2003c: Papp Lászlóval, amiröl még eddig nem beszéltünk. III. Epur si muove. - e-Világ, 2 (4): 34-37.

(http://www.bdarvas.hu/portre/idn3503) (utolsó látogatás: 2021. október 27.)

Lengyel G. 2012: Magyar Természettudományi Múzeum Kétszárnyúak Gyüjteménye http://diptera.nhmus.hu/index-hu.html (utolsó látogatás: 2021. október 27.)

PAPP L. 2021a: Papp László sajátkezü tudományos önéletrajza - Papp János küldeménye (http://bdarvas.hu/download/pdf/1PL_CV.pdf) (utolsó látogatás: 2021. október 27.)

PAPP L. 2021b: New taxa described by László Papp - Papp János küldeménye

(http://bdarvas.hu/download/pdf/2PL_new.pdf) (utolsó látogatás 2021. október 27.)

PAPP L. 2021c: Scientific publications László Papp, 1971-2021 - Papp János küldeménye (http://bdarvas.hu/download/pdf/3PL-IrodList.pdf) (utolsó látogatás 2021. október 27.)

\section{$* * *$ \\ 1. melléklet: \\ Papp László szakirodalmi jegyzéke (válogatta Darvas Béla)*}

\section{Tudományos minösitéshez irt anyagok}

PAPP L. 1975: Trágyában fejlődö legyek komplex vizsgálata. - Kandidátusi értekezés tézisei. MTA Levéltár, Budapest, 15 pp.

* A válogatás Papp László 1971-tól 2021-ig általa vezetett teljes listája alapján készült (PAPP 2021c). 
PAPP L. 1987: A taxonómia eredményeinek felhasználása a legyekkel kapcsolatos gyakorlati feladatok megoldásában. - MTA doktori értekezés tézisei. MTA levéltár. Budapest. 18 pp.

PAPP L. 1993: A repülo" rovarok abundanciájáról (A légyfogás elmélete). - Akadémiai székfoglaló (levelező tag - 1990; 1991. április 30.) In: Értekezések, emlékezések. Akadémiai Kiadó Budapest. 46 pp.

PAPP L. 2000: A legyek ritkaságáról. - In: Székfoglalók a Magyar Tudományos Akadémián 19951998. IV. kötet. Magyar Tudományos Akadémia, Budapest, 31 pp.

\section{Angol nyelvü könyvek}

Papp, L. \& Černý, M. 2015: Agromyzidae (Diptera) of Hungary. Vol. 1: Agromyzinae. - Pars, Hungary, $416 \mathrm{pp}$.

PApp, L. \& Černú, M. 2016: Agromyzidae (Diptera) of Hungary. Vol. 2: Phytomyzinae I. - Pars, Hungary, 385 pp.

PApp, L. \& ČERnÝ, M. 2017: Agromyzidae (Diptera) of Hungary. Vol. 3: Phytomyzinae II. - Pars, Hungary, $427 \mathrm{pp}$.

PApP, L. \& ČERnÝ, M. 2019: Agromyzidae (Diptera) of Hungary. Vol. 4. Phytomyzinae III. - Pars, Hungary, $708 \mathrm{pp}$.

\section{Magyar nyelvü könyvek}

PAPP L. 1973: Trágyalegyek-Harmatlegyek - Sphaeroceridae-Drosophilidae. Magyarország Állatvilága, 15(7). - Akadémiai Kiadó, Budapest, 146 pp.

PAPP L. 1975: Vízilegyek-Ephydridae. Magyarország Állatvilága, 15(6). - Akadémiai Kiadó, Budapest, $129 \mathrm{pp}$.

PAPp L. 1978: Odiniidae-Taplólegyek, Milichiidae-Pákosztoslegyek, Carnidae, Cryptochetidae, Braulidae-Méhtetülegyek, Thyreophoridae; bizonytalan helyzetü torpikkelynélküli légynemek. Magyarország Állatvilága, 15(9). - Akadémiai Kiadó, Budapest, pp. 1-60. és 195-202.

PAPP L. 1979: Korhadéklegyek-Pajzstetülegyek, Lauxaniidae, Chamaemyiidae. Magyarország Állatvilága, 15(4). - Akadémiai Kiadó, Budapest, 89 pp.

PAPP L. 1981: Tüskésszárnyú legyek-Heleomyzidae. Magyarország Állatvilága, 15(5). -Akadémiai Kiadó, Budapest, 77 pp.

Papp L. és Szappanos A. 1992: Bagócslegyek-Gasterophilidae, Oestridae, Hypodermatidae. Magyar Természettudományi Múzeum, Budapest. 56 pp.

\section{Angol nyelvü szerkesztett könyvek}

Soós, Á. \& PAPp, L. (eds ) 1984: Catalogue of Palaearctic Diptera, Vol. 9. MicropezidaeAgromyzidae. - Akadémiai Kiadó \& Elsevier Science Publ., Budapest \& Amsterdam, $460 \mathrm{pp}$.

Soós, Á. \& PAPP, L. (eds) 1984: Catalogue of Palaearctic Diptera, Vol. 10. Clusiidae-Chloropidae. - Akadémiai Kiadó \& Elsevier Science Publ., Budapest \& Amsterdam, 448 pp.

Soós, Á. \& PAPP, L. (eds) 1986: Catalogue of Palaearctic Diptera, Vol. 11. ScathophagidaeHypodermatidae. - Akadémiai Kiadó \& Elsevier Science Publ., Budapest \& Amsterdam, $576 \mathrm{pp}$. 
Soós, Á. \& PApp, L. (eds) 1986: Catalogue of Palaearctic Diptera, Vol. 12. CalliphoridaeSarcophagidae. - Akadémiai Kiadó \& Elsevier Science Publ., Budapest \& Amsterdam, 265 pp.

Soós, Á. \& PAPp, L. (eds) 1986: Catalogue of Palaearctic Diptera, Vol. 4. Sciaridae-Anisopodidae. - Akadémiai Kiadó \& Elsevier Science Publ., Budapest \& Amsterdam, 441 pp.

Soós, Á. \& PAPp, L. (eds) 1988: Catalogue of Palaearctic Diptera, Vol. 3. CeratopogonidaeMycetophilidae. - Akadémiai Kiadó \& Elsevier Science Publ., Budapest \& Amsterdam, 448 pp.

Soós, Á. \& PAPp, L. (eds) 1988: Catalogue of Palaearctic Diptera, Vol. 5. Athericidae-Asilidae. Akadémiai Kiadó \& Elsevier Science Publ., Budapest \& Amsterdam,. 446 pp.

Soós, Á. \& PAPP, L. (eds) 1988: Catalogue of Palaearctic Diptera, Vol. 8. Syrphidae-Conopidae. Akadémiai Kiadó \& Elsevier Science Publ., Budapest \& Amsterdam, 363 pp.

Soós, Á. \& PAPP, L. (eds) 1989: Catalogue of Palaearctic Diptera, Vol. 6. Therevidae-Empididae. Akadémiai Kiadó \& Elsevier Science Publ., Budapest \& Amsterdam, 436 pp.

Soós, Á. \& PAPP, L. (eds) 1990: Catalogue of PalaearcticDiptera, Vol.2. Psychodidae-Chironomidae. - Akadémiai Kiadó \& Elsevier Science Publ., Budapest \& Amsterdam, 499 pp.

Soós, Á. \& PAPp, L. (eds) 1991: Catalogue of Palaearctic Diptera, Vol. 7. DolichopodidaePlatypezidae. - Akadémiai Kiadó \& Elsevier Science Publ., Budapest \& Amsterdam, $292 \mathrm{pp}$.

Soós, Á. \& PAPp, L. (eds) 1992: Catalogue of Palaearctic Diptera, Vol. 1. TrichoceridaeNymphomyiidae. - Akadémiai Kiadó \& Elsevier Science Publ., Budapest \& Amsterdam, 520 pp.

Soós, Á. \& PAPP, L. (eds) 1993: Catalogue of Palaearctic Diptera, Vol. 13. Anthomyiidae-Tachinidae. - Hungarian Natural History Museum, Budapest, 624 pp.

PAPP, L. \& Darvas, B. (eds) 1997: Contributions to a Manual of Palaearctic Diptera. Volume 2: Nematocera and Lower Brachycera. - Science Herald, Budapest, 592 pp.

PAPP, L. \& DA RVAs, B. (eds) 1998: Contributions to a Manual of Palaearctic Diptera, Vol. 3: Higher Brachycera. - Science Herald, Budapest, 880 pp.

PAPp, L. \& Darvas, B. (eds) 2000: Contributions to a Manual of Palaearctic Diptera, Vol. 1: General and Applied Dipterology. - Science Herald, Budapest, 978 pp.

Papp, L. \& Darvas, B. (eds) 2000: Contributions to a Manual of Palaearctic Diptera, Vol. 4: Appendix. - Science Herald, Budapest, 604 pp.

PAPP, L. (ed.). 2001: Checklist of the Diptera of Hungary. - Hungarian Natural History Museum, Budapest 550 pp.

\section{Angol nyelvü szakcikkek}

PAPP, L. 1971: Ecological and production biological data on the significance of flies breeding in cattle droppings. - Acta Zoologica Academicae Scientiarum Hungariae 17: 91-105.

PAPP, L. 1975: House fly larvae as protein source from pig manure. - Folia entomolica hungarica 28: 127-136.

PAPP, L. 1979: On apterous and reduced-winged forms of the families Drosophilidae, Ephydridae and Sphaeroceridae (Diptera). - Acta Zoologica Academicae Scientiarum Hungariae 25: 357-374. 
PAPP, L. 1984: Notes on the bionomics of Agromyza nana (Dipt., Agromyzidae) in Hungary. Zeitschrift für Angewandte Entomologie 87 (3): 280-286.

DARVAS, B. \& PAPP, L. 1985: The morphology of agromyzid pests on wheat and barley in Hungary (Diptera: Agromyzidae). - Acta Zoologica Academicae Scientiarum Hungariae 31(1-3): 97-110.

PAPP, L. 1985: Flies (Diptera) developing in sheep droppings in Hungary. - Acta Zoologica Academicae Scientiarum Hungariae 31(4): 367-379.

BAlOgh, J. \& PAPP, L. 1988: How to avoid unprofitable debate on systematics among taxonomists. - Opuscula zoologica, Budapest 23: 83-92.

Kovács, Sz. F., Medveczky, I., PA Pp, L. \& Gondár, E. 1990: Role of prestomal teeth in feeding of the house fly, Musca domestica (Diptera: Muscidae). - Medical and Veterinary Entomology 4: 331-335.

Szappanos, A. \& PAPp, L. 1992: Bot flies and warble flies (Diptera: Gasterophilidae, Oestridae, Hypodermatidae) in the collection of the Hungarian Natural History Museum. II. Larvae. - Parasitologica hungarica 24: 89-98.

IzsÁK, J. \& PAPP, L. 1994: Numerical properties of jackknifed diversity indices tested on loose sets of coenological samples (Diptera, Drosophilidae). - Coenoses 9(2): 59-67.

IzsÁK, J. \& PAPP, L. 1995: Application of the quadratic entropy indices for diversity studies on drosophilid assemblages. - Environmental and Ecological Statistics 2: 213-224.

PAPP, L. \& IzsÁK, J. 1997: Bimodality in occurrence classes: a direct consequence of lognormal or logarithmic series distribution of abundances - a numerical experimentation. - Oikos 79(1): 191-194.

IzsÁK, J. \& PAPp, L. 1998: On diversity and concentration indices in ecology. - Coenoses 13(1): 29-32.

PAPP, L. 1999: “Outlaws": some evolutionary aspects of rarity in insects. - Tiscia 31: 29-33.

Darvas, B. \& PAPp, L. 2000: Introduction of exotic pests, pp 693-750. In: Papp, L. \& Darvas, B. (eds) Contributions to a Manual of Palaearctic Diptera, Vol. 1: General and Applied Dipterology. - Science Herald, Budapest, 604 pp.

IZsÁ K, J. \& PAPP, L. 2000: A link between ecological diversity indices and measures of biodiversity. - Ecological Modelling 130(1-3): 151-156.

Darvas, B., Andersen, A., Szappanos, A. \& Papp, L. 2000: Developmental biology and larval morphology of Chromatomyia fuscula (Zetterstedt) (Dipt., Agromyzidae). - Acta Zoologica Academicae Scientiarum Hungariae 46 (3): 181-195.

IzsÁ K, J. \& PAPP, L. 2002: Sensitivity of diversity indices: a study of dipterous assemblages. Community Ecology 3(1): 79-86.

PAPP, L. 2004: Description of the first apterous genus of Sciomyzidae (Diptera), from Nepal. Revue suisse de Zoologie 111(1): 57-62.

PAPP, L. \& IzsÁ , J. 2008: Diversity and abundance relationships in a fly collection from a salt lake in central Hungary. - Community Ecology 9(1): 99-105.

PAPP, L. 2008: Will the elephant dung flies go extinct after the elephants disappear? - Folia entomologica hungarica 69: 221-228. 


\section{Magyar nyelvü szakcikkek}

PAPP L. 1983: A zootaxonómia hatékonyságának egyes kérdései. - Állattani Közlemények 70: $63-67$.

PAPP L. 1987: A taxonómia és a szisztematika viszonyáról. - Állattani Közlemények 73: 61-68.

PAPP L. 1988: A parazitológia egyes szünbiológiai fogalmairól. - Parasitologica hungarica 20: $17-31$.

DARVAS B., Szarukán I. és PA PP L. 1988: A póréhagymafej-aknázólégy, Napomyza gymnostoma Loew (Dipt., Agromyzidae) károsítása Magyarországon. - Növényvédelem 24(10): 450-455.

PAPP L. 1994: A zootaxonómia („zoológia”) száz éve és bizonytalan jövője. - Magyar Tudomány 12: $1428-1436$.

\section{2. melléklet:}

\section{Papp László által felállított család-, génusz- és fajcsoport nevek listája}

Az alábbi lista Papp László nyilvántartása alapján készült és a szükséges egységesítésen és szerkesztésen kívül szándékosan semmilyen tartalmi változtatásra nem került sor. A leírások megjelenése alapján időrendbe állított családcsoport nevek kis kapitálissal, a génuszcsoport nevek kövér dőlt, a fajcsoport nevek normál dőlt betűkkel jelezve. A listában csak a fajcsoport-nevek vannak sorszámozva. A lista végén a még meg nem jelent, de a nyilvántartásban szereplő fajcsoport neveket a csillag után „in litteris” megjegyzés jelöli.

1. Drosophila (Lordiphosa) hexasticha L. Papp, 1971

2. Pterogramma insularis L. Papp, 1972

Pterogrammoides L. Papp, 1972

3. Pterogrammmoides baloghi L. Papp, 1972

4. Pterogrammmoides longipennis L. Papp, 1972

5. Pterogrammmoides poecilosomus L. Papp, 1972

Insulomyia L. Papp, 1972

6. Insulomyia brachystoma L. Papp, 1972

7. Insulomyia microps L. Papp, 1972

8. Insulomyia novaeguineae L. Papp, 1972

9. Leiomyza kaszabi L. Papp, 1972

10. Phlebosotera mirabilis L. Papp, 1972

11. Phlebosotera kaszabi L. Papp, 1972

12. Phlebosotera asiatica L. Papp, 1972

13. Phlebosotera nigroscutellata L. Papp, 1972

14. Camilla mongolica L. Papp, 1972

15. Camilla seticosta L. Papp, 1972

Anarista L. Papp, 1972
16. Anarista endroedyi L. Papp, 1972

17. Ischiolepta oedopoda L. Papp, 1972

18. Ischiolepta horrida L. Papp, 1973

19. Ischiolepta longispina L. Papp, 1973

Copromyza (Richardsia) L. Papp, 1973

20. Copromyza (Richardsia) mongolica L. Papp, 1973

21. Copromyza (Borborillus) cryptica L. Papp, 1973

22. Copromyza (Borborillus) micropyga L. Papp, 1973

23. Copromyza (Borborillus) somogyii L. Papp, 1973

24. Copromyza (Copromyza) parastercoraria L. Papp, 1973

25. Coproica dentata L. Papp, 1973

26. Philocoprella mongolica L. Papp, 1973

27. Philocoprella rectiradiata L. Papp, 1973

Paralimosina L. Papp, 1973

28. Paralimosina kaszabi L. Papp, 1973 
29. Limosina clarae L. Papp, 1973

30. Limosina brunneiptera L. Papp, 1973

31. Limosina divergens L. Papp, 1973

32. Limosina duplisetaria L. Papp, 1973

33. Limosina eclecta L. Papp, 1973

34. Limosina glabrocercata L. Papp, 1973

35. Limosina interima L. Papp, 1973

36. Limosina kaszabi L. Papp, 1973

37. Limosina lineatarsata L. Papp, 1973

38. Limosina paralineatarsata L. Papp, 1973

39. Limosina longicornuta L. Papp, 1973

40. Limosina microtophila L. Papp, 1973

41. Limosina paraczizeki L. Papp, 1973

42. Limosina paraflavipes L. Papp, 1973

43. Limosina paralbinervis L. Papp, 1973

44. Limosina pseudoalbinervis L. Papp, 1973

45. Limosina parapenetralis L. Papp, 1973

46. Limosina paratalparum L. Papp, 1973

47. Limosina paravitripennis L. Papp, 1973

48. Limosina pseudoluteilabris L. Papp, 1973

49. Limosina pseudosetitarsalis L. Papp, 1973

50. Limosina pteremoides L. Papp, 1973

51. Limosina puncticorpoides L. Papp, 1973

52. Limosina setilaterata L. Papp, 1973

53. Limosina setitarsalis L. Papp, 1973

54. Limosina spinifemorata L. Papp, 1973

55. Limosina unica L. Papp, 1973

56. Leptocera (Pteremis) ssp. mongolica L. Papp, 1973

57. Leptocera (Pteremis) kaszabi L. Papp, 1973

58. Leptocera (Opacifrons) mirabilis L. Papp, 1973

59. Leptocera (Rachispoda) duodecimseta L. Papp, 1973

60. Leptocera (Rachispoda) microarista L. Papp, 1973

61. Leptocera (Rachispoda) paralutosa L. Papp, 1973

62. Leptocera (Rachispoda) spinicaudata L. Papp, 1973

63. Leptocera (Leptocera) equispina L. Papp, 1973

64. Leptocera (Leptocera) parafinalis L. Papp, 1973

65. Leptocera (Leptocera) spinitarsata L. Papp, 1973
66. Asteia indica L. Papp, 1974

67. Asteia vietnamensis L. Papp, 1974

68. Atissa kerteszi L. Papp, 1974

69. Allotrichoma bifida L. Papp, 1974

70. Allotrichoma schumanni L. Papp, 1974

71. Pelina similis L. Papp, 1974

72. Puncticorpus susannae L. Papp, 1974

73. Crumomyia (Crumomyia) pollinodorsata L. Papp, 1974

74. Limosina macrosetitarsalis L. Papp, 1974

75. Limosina meszarosi L. Papp, 1974

76. Limosina parafungicola L. Papp, 1974

77. Limosina similissima L. Papp, 1974

78. Leptocera (Opacifrons) ochrea L. Papp, 1974

79. Leptocera (Rachispoda) gobiensis L. Papp, 1974

80. Leptocera (Rachispoda) pseudocilifera L. Papp, 1974

81. Leptocera (Rachispoda) spinisternata L. Papp, 1974

82. Archiborborus argentinensis L. Papp, 1977

83. Typopsilopa kerteszi L. Papp, 1975

84. Lytogaster minima L. Papp, 1975

85. Scatophila nasuta L. Papp, 1975

86. Scatophila poeciloptera L. Papp, 1975

87. Copromyza (Borborillus) szelenyii L. Papp, 1974

88. Phyllomyza mongolica L. Papp, 1976

89. Leptometopa kaszabi L. Papp, 1976

90. Meoneura asiatica L. Papp, 1976

91. Meoneura inversa L. Papp, 1976

92. Meoneura kaszabi L. Papp, 1976

93. Meoneura mongolica L. Papp, 1976

94. Meoneura paraseducta L. Papp, 1976

95. Meoneura parva L. Papp, 1976

96. Meoneura pseudoseducta L. Papp, 1976

97. Meoneura pseudotriangularis L. Papp, 1976

98. Meoneura quadrisetosa L. Papp, 1976

99. Meoneura setipyga L. Papp, 1976

100. Copromyza (Copromyza) pseudostercoraria L.

Papp, 1976

101. Odinia photophila L. Papp, 1977

102. Milichia pseudoludens L. Papp, 1977

103. Meoneura carpathica L. Papp, 1977 
104. Meoneura hungarica L. Papp, 1977

105. Meoneura minuscula L. Papp, 1977

106. Meoneura paralacteipennis L. Papp, 1977

107. Elachisoma euphorbiae L. Papp, 1977

108. Limosina baezi L. Papp, 1977

109. Leptocera (Pteremis) canaria L. Papp, 1977

110. Risa mongolica L. Papp, 1977

111. Ceroptera ghanensis L. Papp, 1977

Archiceroptera L. Papp, 1977

112. Archiceroptera mahunkai L. Papp, 1977

Risida E L. Papp, 1977

113. Limosina dudai L. Papp, 1978

114. Limosina ghaznavi L. Papp, 1978

115. Limosina rohaceki L. Papp, 1978

116. Leptocera (Rachispoda) afghanica L. Papp, 1978

117. Leptocera (Rachispoda) ariana L. Papp, 1978

118. Leptocera (Rachispoda) gel L. Papp, 1978

119. Leptocera (Rachispoda) kabuli L. Papp, 1978

120. Leptocera (Rachispoda) meges L. Papp, 1978

121. Leptocera (Rachispoda) micropyga L. Papp, 1978

122. Coproica coreana L. Papp, 1979

123. Coproica ghanensis L. Papp, 1979

124. Leptocera (Opacifrons) tunisica L. Papp, 1977

Katacamilla L. Papp, 1978

125. Katacamilla cavernicola L. Papp, 1978

126. Leptometopa aelleni L. Papp, 1978

127. Asteia afghanica L. Papp, 1979

128. Asteia floricola L. Papp, 1979

129. Asteia tunisica L. Papp, 1979

130. Asteia regalis L. Papp, 1979

Asteia (Subanarista) L. Papp, 1979

131. Asteia (Subanarista) mabunkai L. Papp, 1979

132. Sapromyza afghanica L. Papp, 1979

133. Sapromyza kabuli L. Papp, 1979

134. Sphaerocera breviradiata L. Papp, 1978

135. Afromyia flavimana L. Papp, 1978

136. Afromyia ghanensis L. Papp, 1978

Parasphaerocera (Taigetomyia) L. Papp, 1978

137. Parasphaerocera (Taigetomyia) parva L. Papp, 1978

138. Parasphaerocera andrassyi L. Papp, 1978
139. Parasphaerocera costaricensis L. Papp, 1978

140. Parasphaerocera baloghi L. Papp, 1978

141. Parasphaerocera facialis L. Papp, 1978

142. Parasphaerocera paraflavicoxa L. Papp, 1978

143. Parasphaerocera paratransversa L. Papp, 1978

144. Parasphaerocera subdissecta L. Papp, 1978

145. Parasphaerocera subguttula L. Papp, 1978

146. Parasphaerocera zicsii L. Papp, 1978

Trichosphaerocera L. Papp, 1978

147. Trichosphaerocera africana L. Papp, 1978

148. Lotobia endroedyi L. Papp, 1978

149. Lotobia kovacsi L. Papp, 1978

150. Ischiolepta similis L. Papp, 1978

151. Ischiolepta vanschuytbroecki L. Papp, 1978

152. Homoneura maghrebi L. Papp, 1978

153. Homoneura remmi L. Papp, 1978

154. Homoneura shewelliana L. Papp, 1978

155. Homoneura subnotata L. Papp, 1978

156. Homoneura thalhammeri L. Papp, 1978

157. Homoneura tunisica L. Papp, 1978

Sapromyza (Schumannimyia) L. Papp, 1978

Lauxania (Callixania) L. Papp, 1978

158. Lyciella mihalyii L. Papp, 1978

159. Lyciella stylata L. Papp, 1978

160. Lyciella subpallidiventris L. Papp, 1978

161. Calliopum splendidum L. Papp, 1978

162. Thoracochaeta tunisica L. Papp, 1978

163. Meoneura tunisica L. Papp, 1978

Copromyza (Dudaborborus) L. Papp, 1979

164. Copromyza (Dudaborborus) schumanni L. Papp, 1979

165. Hypselothyrea aptera L. Papp, 1979

Tauromima L. Papp, 1979

166. Tauromima mountwilhelmi L. Papp, 1979

167. Scatophila stenoptera L. Papp, 1979

Reunionia L. Papp, 1979

168. Reunionia unica L. Papp, 1979

Hackmania L. Papp, 1979

169. Hackmania ceylanica L. Papp, 1979

Apterobiroina L. Papp, 1979

170. Apterobiroina australis L. Papp, 1979

171. Limosina terrestris L. Papp, 1979

172. Leptocera (Opacifrons) elbergi L. Papp, 1979 
173. Leptocera (Rachispoda) excavata L. Papp, 1979

174. Leptocera (Rachispoda) praeapicalis L. Papp, 1979

175. Leptocera (Rachispoda) sajanica L. Papp, 1979

176. Meoneura subfreta L. Papp, 1979

177. Hemeromyia afghanica L. Papp, 1979

178. Limosina karelica L. Papp, 1979

179. Oldenbergiella calcarifera L. Papp, 1980

180. Oldenbergiella seticerca L. Papp, 1980

181. Oecothea hungarica L. Papp, 1980

182. Meoneura moravica Gregor et L. Papp, 1981

Tunisimyiddae L. Papp, 1980

Tunisimyia L. Papp, 1980

183. Tunisimyia excellens L. Papp, 1980

Achaetorisa L. Papp, 1980

184. Achaetorisa brevicornis L. Papp, 1980

185. Risa longicornuta L. Papp, 1980

Nannodastinnae L. Papp, 1980

186. Azorastia mediterranea L. Papp, 1980

187. Homoneura pseudolimnea L. Papp, 1981

188. Calliopum tunisicum L. Papp, 1981

189. Lyciella brevimana L. Papp, 1981

190. Sapromyza gozmanyi L. Papp, 1981

191. Sapromyza (Sapromyzosoma) maghrebi L. Papp, 1981

192. Minettia cypriota L. Papp, 1981

193. Minettia graeca L. Papp, 1981

194. Minettia bulgarica L. Papp, 1981

195. Minettia palaestinensis L. Papp, 1981

196. Minettia subtinctipennis L. Papp, 1981

197. Minettia tunisica L. Papp, 1981

198. Meoneura atoma L. Papp, 1981

199. Meoneura flavifrons L. Papp, 1981

Indiosina L. Papp, 1981

200. Indiosina loebli L. Papp, 1981

Minocellina L. Papp, 1981

201. Minocellina besucheti L. Papp, 1981

STENomicridae L. Papp, 1984

202. Rhynchomicropteron brevipes L. Papp, 1982

203. Rhynchomicropteron dudichi L. Papp, 1982

204. Rhynchomicropteron nudiventer L. Papp, 1982
205. Paralimosina anaptera Papp et Rohácek, 1981 206. Paralimosina franzi Papp et Rohácek, 1981

207. Paralimosina gomerensis Papp et Rohácek, 1981

208. Paralimosina pilifemorata Papp et Rohácek, 1981

209. Camilla sabroskyi L. Papp, 1982

210. Bibio elmoi L. Papp, 1982

Subpelignus L. Papp, 1983

211. Subpelignus hortobagyensis L. Papp, 1983

212. Hydrellia asymmetrica L. Papp, 1983

213. Hydrellia minutissima L. Papp, 1983

214. Hydrellia parafrontosa L. Papp, 1983

215. Paralimosina avolans Rohácek et L. Papp, 1983

216. Crumomyia (Crumomyia) glacialis gallica L. Papp et Rohácek, 1983

217. Crumomyia (Crumomyia) parentela alpicola L. Papp et Rohácek, 1983

218. Elachisoma bajzae L. Papp 1983

219. Elachisoma braacki L. Papp 1983

220. Elachisoma afrotropicum L. Papp 1983

Leptocera (Nipponsina) L. Papp, 1982

221. Leptocera (Nipponsina) sexsetosa L. Papp, 1982

222. Leptocera dyscola Rohácek et L. Papp, 1983

223. Leptocera vomerata Rohácek et L. Papp, 1983

224. Homoneura koreana L. Papp, 1984

225. Homoneura shatalkini L. Papp, 1984

226. Homoneura stackelbergiana L. Papp, 1984

227. Homoneura stigmata L. Papp, 1984

228. Homoneura lushanica L. Papp, 1984

229. Calliopum ceianui L. Papp, 1984

Lyciella (Shatalkinia) L. Papp, 1984

230. Lyciella (Shatalkinia) supraorientalis L. Papp, 1984

231. Camilla mathisi L. Papp, 1985

232. Phyllomyza aelleni L. Papp, 1984

233. Leptometopa pacifica L. Papp, 1984

234. Leptometopa pecki L. Papp, 1984

235. Ischiolepta loebli Rohácek et Papp, 1984

236. Ischiolepta draskovitsae Rohácek et Papp, 1984 
237. Odinia (Turanodinia) tisciae L. Papp, 1987

238. Sapromyza (Sapromyza) schnabli L. Papp, 1987

239. Mycterella luteofasciata Yarom, Freidberg et Papp, 1987

240. Mycterella nigra Yarom, Freidberg et Papp, 1987

241. Copromyza norrbomi L. Papp, 1988 (to Lotophila)

242. Sphaerocera pseudomonilis asiatica L. Papp, 1988

Norrbomia L. Papp, 1988

243. Norrbomia indica L. Papp, 1988

244. Norrbomia demeteri L. Papp, 1988

245. Norrbomia elephantis L. Papp, 1988

246. Norrbomia keniaca L. Papp, 1988

247. Norrbomia sarcophaga L. Papp, 1988

248. Paralimosina acris Rohácek et L. Papp, 1988

249. Paralimosina bracteata Rohácek et L. Papp, 1988

250. Paralimosina brevis Rohácek et L. Papp, 1988

251. Paralimosina dimorpha Rohácek et L. Papp, 1988

252. Paralimosina gigantea Rohácek et L. Papp, 1988

253. Paralimosina icaros Rohácek et L. Papp, 1988

254. Paralimosina indica Rohácek et L. Papp, 1988

255. Paralimosina lobata Rohácek et L. Papp, 1988

256. Paralimosina marshalli Rohácek et L. Papp, 1988

257. Paralimosina minor Rohácek et L. Papp, 1988

258. Periscelis kabuli L. Papp, 1988

259. Periscelis kaszabi L. Papp, 1988

260. Minocellina thaii L. Papp, 1989

261. Poecilosomella arnaudi L. Papp, 1990

262. Poecilosomella capensis L. Papp, 1990

263. Pterogrammoides indica L. Papp, 1989

264. Pterogrammoides thaii L. Papp, 1989

265. Poecilosomella cryptica L. Papp, 1991

266. Peplominettia milleri L. Papp, 1991

267. Terrilimosina intricata L. Papp, 1991

268. Aptilotus appendix L. Papp, 1991

269. Opalimosina stepheni L. Papp, 1991
270. Opacifrons brevisecunda L. Papp, 1991

271. Opacifrons cederholmi L. Papp, 1991

272. Paralimosina eximia L. Papp, 1991

273. Leptocera (Leptocera) stenodiscoidalis L. Papp, 1991

Parascutops Mathis et L. Papp, 1992

274. Achaetothorax acrostichalis L. Papp et Norrbom, 1992

275. Achaetothorax crypticus L. Papp et Norrbom, 1992

276. Achaetothorax flavipes L. Papp et Norrbom, 1992

277. Achaetothorax malayensis L. Papp et Norrbom, 1992

278. Achaetothorax trochanteratus L. Papp et Norrbom, 1992

279. Achaetothorax vojnitsi L. Papp et Norrbom, 1992

280. Gymnomus czernyi L. Papp et Woznica, 1993

281. Gymnomus gorodkovi L. Papp et Woznica, 1993

282. Gymnomus europaeus L. Papp et Woznica, 1993

283. Gymnomus martineki L. Papp et Woznica, 1993

284. Gymnomus mongolicus L. Papp et Woznica, 1993

285. Gymnomus soosi L. Papp et Woznica, 1993

286. Madiza eximia L. Papp, 1993

287. Desmometopa discipalpis L. Papp, 1993

288. Paramyia hungarica L. Papp, 1993

289. Ischiolepta indica L. Papp, 1993

290. Ischiolepta minuscula L. Papp, 1993

291. Schroederella bifida L. Papp et Carles-Tolrá, 1994

292. Schroederella hispanica L. Papp et CarlesTolrá, 1994

293. Schroederella bungarica L. Papp et CarlesTolrá, 1994

294. Schroederella minuta L. Papp et Carles-Tolrá, 1994

295. Achaetothorax completus Norrbom et L. Papp, 1994 
296. Achaetothorax concavus Norrbom et L. Papp, 1994

297. Achaetothorax coninckae Norrbom et L. Papp, 1994

298. Achaetothorax grootaerti Norrbom et L. Papp, 1994

299. Achaetothorax medialis Norrbom et L. Papp, 1994

300. Achaetothorax pectinatus Norrbom et L. Papp, 1994

301. Achaetothorax whittingtoni Norrbom et L. Papp, 1994

302. Cremifania lanceolata L. Papp, 1994

303. Biroina burckhardti L. Papp, 1995

304. Biroina orientalis L. Papp, 1995

305. Biroina topali L. Papp, 1995

Tauridion L. Papp \& Silva, 1995

306. Tauridion shewelli L. Papp \& Silva, 1995

Bacilloflagellomera L. Papp \& Silva, 1995

307. Bacilloflagellomera pectinicornis L. Papp \& Silva, 1995

Paraphysoclypeus L. Papp \& Silva, 1995

308. Paraphysoclypeus nigropleura L. Papp \& Silva, 1995

Gibbolauxania L. Papp \& Silva, 1995

309. Gibbolauxania elegans L. Papp \& Silva, 1995

Baliopteridion L. Papp \& Silva, 1995

310. Baliopteridion brevitarsus L. Papp \& Silva, 1995

Pseudominettia L. Papp \& Silva, 1995

311. Pseudominettia platypeza L. Papp \& Silva, 1995

Minilauxania L. Papp \& Silva, 1995

312. Minilauxania bulbifacies L. Papp \& Silva, 1995

313. Meoneura carpathica pseudoflavifacies L. Papp, 1997

314. Meoneura falcata L. Papp 1997

315. Meoneura helvetica L. Papp 1997

316. Meoneura longifurca L. Papp 1997

Kimiella L. Papp, 1997

317. Kimiella simplex L. Papp \& Kim, 1997

318. Kimiella spatulifer L. Papp \& Kim, 1997
319. Kimiella grisea Kim \& L. Papp, 1997

Lyciovibrissina L. Papp \& Kim, 1997

320. Lyciovibrissina minor L. Papp \& Kim, 1997

Celyphohomoneura L. Papp \& Kim, 1997

321. Celyphohomoneura nitida Papp \& Kim, 1997

322. Celyphohomoneura nigrifacies Kim \& Papp, 1997

323. Sphyracephala europaea Papp et Földvári, 1997

324. Aulacigaster afghanorum L. Papp, 1998

325. Aulacigaster falcata L. Papp, 1998

326. Periscelis chinensis L. Papp et Szappanos, 1998

Nidomyinn L. Papp, 1998

Nidomyia L. Papp, 1998

327. Nidomyia cana L. Papp, 1998

328. Scaptodrosophila abdita L. Papp, Rácz et Bächli, 1999

329. Prosopantrum acrostichale L. Papp, 1999

330. Prosopantrum congolense L. Papp, 1999

331. Prosopantrum demeteri L. Papp, 1999

332. Leucophenga hungarica L. Papp, 2000

333. Stegana (Steganina) consimilis L. Papp et Máca, 2000

334. Crumomyia microps Rohácek et L. Papp, 2000

335. Crumomyia cavernicola oculea Rohácek et $\mathrm{L}$. Papp, 2000

336. Paramyia africana L. Papp, 2002

337. Paramyia flagellomera L. Papp, 2002

338. Paramyia flava L. Papp, 2002

339. Paramyia formosana L. Papp, 2002

340. Paramyia latigena L. Papp, 2002

341. Paramyia longilingua L. Papp, 2002

342. Paramyia minuscula L. Papp, 2002

343. Paramyia nitida L. Papp, 2002

344. Paramyia palpalis L. Papp, 2002

345. Paramyia regalis L. Papp, 2002

346. Paramyia setitarsalis L. Papp et Swann, 2002

347. Paramyia swanni L. Papp, 2002

348. Paramyia triangularis L. Papp, 2002

Paramyioides L. Papp, 2002

349. Paramyioides perlucida L. Papp, 2002 
350. Tachypeza yinyang L. Papp et Földvári, 2002

351. Megagrapha europaea L. Papp et Földvári, 2002

Chvalaea L. Papp et Földvári, 2002

352. Chvalaea sopianae L. Papp et Földvári, 2002

353. Dynatosoma nigripes Ševčík et L. Papp, 2001

354. Nannodastia atlantica L. Papp et Mathis, 2001

355. Aldrichiomyza koreana L. Papp, 2001

356. Poecilosomella brevisecunda L. Papp, 2002

357. Poecilosomella borborus L. Papp, 2002

358. Poecilosomella conspicua L. Papp, 2002

359. Poecilosomella curvipes L. Papp, 2002

360. Poecilosomella formosana L. Papp, 2002

361. Poecilosomella hayashii L. Papp, 2002

363. Poecilosomella longicalcar L. Papp, 2002

364. Poecilosomella nigra L. Papp, 2002

365. Poecilosomella paraciculata L. Papp, 2002

366. Poecilosomella paracryptica L. Papp, 2002

367. Poecilosomella peniculifera L. Papp, 2002

368. Poecilosomella pilimana L. Papp, 2002

369. Poecilosomella pilipino L. Papp, 2002

370. Poecilosomella ronkayi L. Papp, 2002

371. Poecilosomella sabahi L. Papp, 2002

372. Poecilosomella spinicauda L. Papp, 2002

373. Poecilosomella spinipes L. Papp, 2002

374. Poecilosomella subhimalayensis L. Papp, 2002

Matileola L. Papp, 2002

375. Matileola yangi L. Papp, 2002

376. Lygistorrhina chaoi L. Papp, 2002

377. Turanodinia nigripalpis L. Papp, 2002

378. Ischiolepta baloghi L. Papp, 2003

379. Ischiolepta peregovitsi L. Papp, 2003

380. Crumomyia topali L. Papp, 2003

381. Norrbomia nepalensis L. Papp, 2003

382. Metaborborus flavior orientalis L. Papp, 2003

383. Mycomya vaisaneni L. Papp, 2003

384. Diadocidia setistylus L. Papp, 2003

385. Symballophthalmus inermis L. Papp, 2003

386. Chamaepsila triorbiseta L. Papp, 2003

387. Hemeromyia vibrissina L. Papp, 2003

388. Leia hungarica Ševčík et L. Papp, 2003

389. Leia martinovskyi Ševčík et L. Papp, 2003
390. Allodiopsis gracai Ševčík et L. Papp, 2003

Apteromicra L. Papp, 2004

391. Apteromicra parva L. Papp, 2004

392. Hypselothyrea africana L. Papp, 2004

393. Hypselothyrea decipiens L. Papp, 2004

394. Hypselothyrea mixta L. Papp, 2004

395. Hypselothyrea paralanigera L. Papp, 2004

396. Hypselothyrea paratenuis L. Papp, 2004

397. Hypselothyrea (Deplanothyrea) amputata L. Papp, 2004

398. Hypselothyrea (Deplanothyrea) formosana L. Papp, 2004

399. Hypselothyrea (Deplanothyrea) longimana L. Papp, 2004

400. Hypselothyrea (Deplanothyrea) subaptera L. Papp, 2004

Aspinilimosina L. Papp, 2004

401. Aspinilimosina postocellaris L. Papp, 2004

Pellucialula L. Papp, 2004

402. Pellucialula polyseta L. Papp, 2004

Immoderatus L. Papp, 2004

403. Immoderatus foldvarii L. Papp, 2004

Sciarokeroplatinae L. Papp, 2005

Sciarokeroplatus L. Papp \& Ševčík, 2005

404. Sciarokeroplatus pileatus L. Papp \& Ševčík, 2005

405. Schumannimyia pseudobyalinata L. Papp, 2004

406. Bolitophila (Bolitophila) antennata Ševčík et Papp, 2004

407. Bolitophila (Cliopisa) taibybrida Ševčík et Papp, 2004

408. Eumanota jani L. Papp, 2004

409. Eumanota parabumeralis L. Papp, 2004

410. Promanota formosana L. Papp, 2004

411. Manota bilobata L. Papp, 2004

412. Manota delyorum L. Papp, 2004

413. Manota meilingae L. Papp, 2004

414. Paramanota schachti L. Papp, 2004

415. Lotobia asiatica Hayashi et Papp, 2004

416. Lotobia latipes Hayashi et Papp, 2004

417. Lotobia supraelegans Hayashi et Papp, 2004

Macalpinella L. Papp, 2005 
418. Macalpinella brevifacies L. Papp, 2005

419. Xenasteia chinensis L. Papp, 2005

420. Acrometopia conspicua L. Papp, 2005

421. Chamaemyia taiwanensis L. Papp, 2005

422. Campichoeta spinicauda L. Papp, 2005

423. Apolysis szappanosi L. Papp, 2005

424. Trixoscelis fumipennis L. Papp, 2005

425. Trixoscelis margo L. Papp, 2005

426. Matileola thaii L. Papp, 2005

427. Matileola similis L. Papp, 2005

428. Lygistorrbina pentafida L. Papp, 2005

Taidocidia L. Papp \& Ševč́́k, 2005

429. Taidocidia globosa L. Papp \& Ševčík, 2005

430. Diadocidia sevciki L. Papp, 2005

Curiosimusca Rung, Mathis \& Papp, 2005

431. Curiosimusca khooi Rung, Mathis \& Papp, 2005

432. Curiosimusca maefangensis Rung, Mathis \& Papp, 2005

433. Curiosimusca orientalis Rung, Mathis \& Papp, 2005

Asiodixa L. Papp, 2006

Bisubcosta L. Papp, 2006

Stenocyamops L. Papp, 2006

Paramyioides (Spinitrochanter) L. Papp, 2006

434. Asiodixa maculata L. Papp, 2006

435. Asiodixa pura L. Papp, 2006

436. Thaumalea nigronitida L. Papp, 2006

437. Mesochria thaii L. Papp, 2006

438. Bisubcosta oligoneura L. Papp, 2006

439. Heteropterna oroszi L. Papp, 2006

440. Heteropterna thaii L. Papp, 2006

441. Platyroptilon jarujini L. Papp, 2006

442. Setostylus alienus L. Papp, 2006

443. Xenokeroplatus continentalis L. Papp, 2006

444. Lycosepsis biseta L. Papp, 2006

445. Lycosepsis oedipus L. Papp, 2006

446. Formicosepsis paratinctipennis L. Papp, 2006

447. Strongylophthalmyia dorsocentralis L. Papp, 2006

448. Strongylophthalmyia macrocera L. Papp, 2006

449. Strongylophthalmyia palpalis L. Papp, 2006
450. Strongylophthalmyia thaii L. Papp, 2006

451. Noonamyia sasakawai L. Papp, 2006

452. Spaniocelypus paradentatus L. Papp, 2006

453. Odinia thaii L. Papp, 2006

454. Aldrichiomyza iwasai L. Papp, 2006

455. Paramyioides (Spinitrochanter) horrida L. Papp, 2006

456. Paramyioides (Spinitrochanter) spinosa L. Papp, 2006

457. Campichoeta (Thryptocheta) flavicauda L. Papp, 2006

458. Cyamops fumipennis L. Papp, 2006

459. Stenomicra flava L. Papp, 2006

460. Podocera claripennis L. Papp, 2006

461. Podocera variegata L. Papp, 2006

462. Stenocyamops thaii L. Papp, 2006

463. Meoneura sabroskyi L. Papp, 2006

464. Dixa foldvarii L. Papp, 2007

465. Dixa formosana L. Papp, 2007

466. Dixa nigripleura L. Papp, 2007

467. Dixella pilosiflagellata L. Papp, 2007

468. Protaxymyia taiwanensis L. Papp, 2007

469. Mycetobia formosana L. Papp, 2007

470. Mesochria simplicipes L. Papp, 2007

Xenokeroplatus (Tipulokeroplatus) L. Papp, 2007

471. Xenokeroplatus (Tipulokeroplatus) gozmanyi

L. Papp, 2007

472. Chaetopodella latitarsis Hayashi \& Papp, 2007

473. Chaetopodella nigrinotum Hayashi \& Papp, 2007

474. Chaetopodella orientalis Hayashi \& Papp, 2007

475. Chaetopodella ornata Hayashi \& Papp, 2007

476. Leiomyza chinensis L. Papp, 2007

477. Manota bifida Hippa \& Papp, 2007

478. Manota dentata Hippa \& Papp, 2007

479. Manota forceps Hippa \& Papp, 2007

480. Manota inusitata Hippa \& Papp, 2007

481. Manota mirifica Hippa \& Papp, 2007

482. Manota occulta Hippa \& Papp, 2007

483. Manota secreta Hippa \& Papp, 2007

484. Schroederella kirilli L. Papp, 2007 
485. Schroederella media L. Papp, 2007

486. Diplochasma australis L. Papp, 2007

487. Luzonomyza pseudoforficula L. Papp, 2007

488. Luzonomyza sasakawai L. Papp, 2007

489. Luzonomyza vietnamensis L. Papp, 2007

490. Maquilingia biroi L. Papp, 2007

491. Maquilingia thaii L. Papp, 2007

492. Protrigonometopus ornatus L. Papp, 2007

493. Protrigonometopus shatalkini L. Papp, 2007

Shatalkinella L. Papp, 2007

494. Shatalkinella marginata L. Papp, 2007

495. Shatalkinella punctipennis L. Papp, 2007

496. Shatalkinella ronkayi L. Papp, 2007

497. Shatalkinella thailandica L. Papp, 2007

498. Tetroxyrhina peregovitsi L. Papp, 2007

499. Diplochasma (Sauteromyia) albomarginata L. Papp, 2008

500. Diplochasma (Sauteromyia) aphaniosignata L. Papp, 2008

501. Diplochasma (Sauteromyia) clara L. Papp, 2008

502. Diplochasma (Sauteromyia) occidentalis L. Papp, 2008

503. Diplochasma (Sauteromyia) punctata L. Papp, 2008

504. Diplochasma (Sauteromyia) shewelli L. Papp, 2008

505. Diplochasma (Sauteromyia) stuckenbergi L. Papp, 2008

506. Diplochasma (Sauteromyia) variegata L. Papp, 2008

507. Chaetopodella aethiopica L. Papp, 2008

508. Chaetopodella demeteri L. Papp, 2008

509. Chaetopodella nigeriae L. Papp, 2008

Chaetopodella (Afrochaetopodella) L. Papp, 2008

510. Chaetopodella (Afrochaetopodella) keniaca L. Papp, 2008

511. Chaetopodella (Afrochaetopodella) reducta $\mathrm{L}$. Papp, 2008

Micromacrocera L. Papp, 2008

512. Micromacrocera stenobasis L. Papp, 2008

513. Coproica aliena L. Papp, 2008

514. Coproica bispinosa L. Papp, 2008
515. Coproica saprophaga L. Papp, 2008

516. Coproica thaii L. Papp, 2008

517. Coproica unispinosa L. Papp, 2008

518. Coproica albiseta L. Papp, 2008

519. Coproica brevivenosa L. Papp, 2008

520. Coproica demeteri L. Papp, 2008

521. Coproica flavifacies L. Papp, 2008

522. Coproica microps L. Papp, 2008

523. Coproica perlugubris L. Papp, 2008

524. Coproica pseudolacteipennis L. Papp, 2008

525. Grzegorzekia hungarica Papp \& Ševčík, 2007

Afropterogramma L. Papp, 2008

526. Afropterogramma minor L. Papp, 2008

Archipterogrammoides L. Papp, 2008

527. Archipterogrammoides metatarsalis L. Papp, 2008

Australimosina L. Papp, 2008

Biconnecta L. Papp, 2008

528. Biconnecta mirabilis L. Papp, 2008

Cephalimosina L. Papp, 2008

529. Biconnecta simplicipes L. Papp, 2008

Chaetosifemur L. Papp, 2008

530. Chaetosifemur longiventre L. Papp, 2008

Congomyiella L. Papp, 2008

531. Congomyiella ceropteroides L. Papp, 2008

Eximilimosina L. Papp, 2008

532. Eximilimosina major L. Papp, 2008

533. Eximilimosina thailandica L. Papp, 2008

Giraffimyiella L. Papp, 2008

Gonitella L. Papp, 2008

534. Gonitella flavipes L. Papp, 2008

Minialula L. Papp, 2008

535. Minialula poeciloptera L. Papp, 2008

Mixolimosina L. Papp, 2008

536. Mixolimosina orientalis L. Papp, 2008

Monorbiseta L. Papp, 2008

Paramera L. Papp, 2008

537. Paramera robusta L. Papp, 2008

538. Paramera ornata L. Papp, 2008

Paraminilimosina L. Papp, 2008

539. Paraminilimosina miraculisterna L. Papp, 2008

540. Paraminilimosina elephantis L. Papp, 2008 
Parapoecilosomella L. Papp, 2008

Parapterogramma L. Papp, 2008

541. Parapterogramma asiatica L. Papp, 2008

Piliterga L. Papp, 2008

542. Piliterga thaii L. Papp, 2008

Pseudacuminiseta L. Papp, 2008

543. Pseudacuminiseta formosana L. Papp, 2008

Pseudaspinilimosina L. Papp, 2008

544. Pseudaspinilimosina tanzan L. Papp, 2008

Pseudopterogramma L. Papp, 2008

545. Pseudopterogramma siamensis L. Papp, 2008

Rohacekia L. Papp, 2008

546. Rohacekia baechlii L. Papp, 2008

Setositibiella L. Papp, 2008

547. Setositibiella terrestris L. Papp, 2008

Thailimosina L. Papp, 2008

548. Thailimosina maculata L. Papp, 2008

Trilobitella L. Papp, 2008

549. Trilobitella taiwanica L. Papp, 2008

Minilimosina (Sagittaliseta) L. Papp, 2008

550. Minilimosina (Sagittaliseta) siamensis L. Papp, 2008

Minilimosina (Amediella) L. Papp, 2008

551. Minilimosina (Amediella) endrodyi L. Papp, 2008

Phthitia (Rufolimosina) L. Papp, 2008

552. Phthitia (Rufolimosina) ornata L. Papp, 2008

553. Phthitia (Rufolimosina) oswaldi L. Papp, 2008

554. Bifronsina elegans L. Papp, 2008

555. Bifronsina latitarsis L. Papp, 2008

556. Bifronsina nepalensis L. Papp, 2008

557. Eulimosina oroszi L. Papp, 2008

Paracuminiseta L. Papp, 2008

558. Paracuminiseta tetrasetosa L. Papp, 2008

559. Hypselothyrea (Deplanothyrea) thaii L. Papp, 2009

560. Hypselothyrea (Deplanothyrea) zulu L. Papp, 2009

Hypselothyrea (Baechlia) L. Papp, 2009

561. Hypselothyrea (Baechlia) hindu L. Papp, 2009

562. Hypselothyrea (Baechlia) nitidipleura L. Papp, 2009
563. Hypselothyrea (Baechlia) verrucosa L. Papp, 2009

Microkeroplatus Ševčík \& Papp, 2009

564. Microkeroplatus longisetosus Ševčík \& Papp, 2009

565. Microkeroplatus minutus Ševčík \& Papp, 2009

566. Microkeroplatus sumatrensis Ševčík \& Papp, 2009

567. Nepaletricha furcata Hippa, Chandler \& Papp, 2009

568. Nepaletricha montana Hippa, Chandler \& Papp, 2009

569. Madiza africana Papp \& Brake, 2009

570. Poecilosomella additionalis L. Papp, 2010

571. Poecilosomella duploseriata L. Papp, 2010

572. Poecilosomella kittenbergeri L. Papp, 2010

573. Poecilosomella occulta L. Papp, 2010

574. Poecilosomella parangulata L. Papp, 2010

575. Poecilosomella setimanus L. Papp, 2010

576. Poecilosomella setosissima L. Papp, 2010

577. Cremifania bulgarica L. Papp, 2010

578. Leptomorphus alienus Papp \& Ševčík, 2011

579. Leptomorphus ascutellatus Papp \& Ševčík, 2011

580. Leptomorphus baramensis Papp \& Ševčík, 2011

581. Leptomorphus gunongmuluensis Papp \& Ševčík, 2011

582. Leptomorphus longipes Papp \& Ševčík, 2011

583. Leptomorphus matilei Papp \& Ševčík, 2011

584. Leptomorphus papua Papp \& Ševčík, 2011

585. Leptomorphus utarensis Papp \& Ševčík, 2011

586. Hesperinus graecus L. Papp, 2010

587. Hesperinus ninae L. Papp \& M. Krivosheina, 2010

Paramorpholeria L. Papp, 2010

589. Paramorpholeria vietnamensis L. Papp, 2010

590. Schroederella stylata L. Papp, 2010

591. Neoalticomerus mongolicus Withers \& Papp, 2012

592. Neoalticomerus fabricius Withers \& Papp, 2012 
593. Periscelis nigra ssp. minor L. Papp \& Withers, 2011

594. Teratomyza formosana L. Papp, 2011

Poecilovitila L. Papp, 2011

595. Poecilovitila barbata L. Papp, 2011

596. Poecilovitila brevicornis L. Papp, 2011

597. Poecilovitila bulbiscapus L. Papp, 2011

598. Poecilovitila defecta L. Papp, 2011

599. Poecilovitila elegans L. Papp, 2011

600. Poecilovitila erugata L. Papp, 2011

601. Poecilovitila hindustanica L. Papp, 2011

602. Poecilovitila japonica L. Papp, 2011

603. Poecilovitila taiwanica L. Papp, 2011

604. Poecilovitila thaii L. Papp, 2011

605. Poecilovitila variegata L. Papp, 2011

Circumphallidae L. Papp, 2011

Circumphallus L. Papp, 2011

606. Circumphallus significans L. Papp, 2011

607. Micrepimera berentiana Ševčík \& Papp, 2011

608. Micrepimera pandastica Ševčík \& Papp, 2011

609. Opacifrons afrobrevisecunda L. Papp, 2012

610. Opacifrons compacta L. Papp, 2012

611. Opacifrons dilatata L. Papp, 2012

612. Opacifrons serrata L. Papp, 2012

613. Opacifrons subserrata L. Papp, 2012

614. Leptocera austroafricana L. Papp, 2012

615. Leptocera inconspicua L. Papp, 2012

616. Abaristophora hirticornis Lengyel \& Papp, 2012

617. Postoptica continentalis Lengyel \& Papp, 2012

618. Paralimosina flavifacies L. Papp, 2013

619. Paralimosina australis L. Papp, 2013

620. Paralimosina paraustralis L. Papp, 2013

621. Paralimosina congoensis L. Papp, 2013

622. Paralimosina heteroneura L. Papp, 2013

623. Paralimosina sinelinea L. Papp, 2013

624. Meoneura indica L. Papp, 2013

625. Meoneura nepalensis L. Papp, 2013

626. Meoneura nigrohalterata L. Papp, 2013

627. Meoneura orientalis L. Papp. 2013

628. Meoneura simplex L. Papp, 2013

629. Meoneura subinversa L. Papp, 2013
630. Homoneura pseudograndis L. Papp \&

Gaimari, 2013

Polyarista L. Papp, 2013

631. Polyarista albistoma L. Papp, 2013

Afrolimosina L. Papp, 2014

632. Afrolimosina albitarsis L. Papp, 2014

Biphallapodema L. Papp, 2014

633. Biphallapodema oligochaeta L. Papp, 2014

634. Biphallapodema polychaeta L. Papp, 2014

Chelilimosina L. Papp, 2014

635. Chelilimosina baloghi L. Papp, 2014

Mislocatus L. Papp, 2014

Oligochaetosella L. Papp, 2014

636. Oligochaetosella inconspicua L. Papp, 2014

Permixtolimosina L. Papp, 2014

637. Permixtolimosina sexsetosa L. Papp, 2014

638. Preepiphallus endrodyi L. Papp, 2014

Preepiphallus L. Papp, 2014

639. Preepiphallus nitidifacies L. Papp, 2014

Subacuminiseta L. Papp, 2014

640. Subacuminiseta minor L. Papp, 2014

641. Ceroptera armata L. Papp, 2014

642. Ceroptera globosa L. Papp, 2014

643. Ceroptera inermis L. Papp, 2014

644. Ceroptera minuscula L. Papp, 2014

645. Ceroptera moroccana L. Papp, 2014

646. Ceroptera nigra L. Papp, 2014

647. Ceroptera setiscutellata L. Papp, 2014

648. Dudaia abdita L. Papp \& Norrbom, 2015

649. Dudaia aethiopica L. Papp \& Norrbom, 2015

650. Dudaia albimana L. Papp \& Norrbom, 2015

651. Dudai brevis L. Papp \& Norrbom, 2015

652. Dudaia communis L. Papp \& Norrbom, 2015

653. Dudaia malagasiensis L. Papp \& Norrbom, 2015

654. Dudaia microtuberculata L. Papp \& Norrbom, 2015

655. Dudaia paralbimana L. Papp \& Norrbom, 2015

656. Dudaia pseudohumeralis L. Papp \& Norrbom, 2015

657. Dudaia spangleri L. Papp \& Norrbom, 2015

658. Coproica ashleyi L. Papp, 2015 
659. Coproica paraunispinosa L. Papp, 2015

Indochinomyia L. Papp, 2016

660. Indochinomyia lao L. Papp, 2016

661. Indochinomyia viet L. Papp, 2016

662. Homoneura sulawesiensis Papp \& Gaimari, (in litteris)

663. Homoneura armatipuga Papp \& Gaimari, (in litteris)

664. Homoneura nigronitida Papp \& Gaimari, (in litteris)

665. Homoneura paranigronitida Papp \& Gaimari, (in litteris)

666. Homoneura pseudonigronitida Papp \& Gaimari, (in litteris)

667. Homoneura subnigronitida Papp \& Gaimari, (in litteris)

668. Agromyza abdita L. Papp, 2015

669. Agromyza breviphallus L. Papp, 2015

670. Agromyza longiphallus L. Papp, 2015

671. Agromyza pseudambigua L. Papp, 2015

672. Agromyza seticercus L. Papp, 2015

673. Agromyza tothi L. Papp, 2015

674. Pseudocollinella marshalli L. Papp, 2016

675. Pseudocollinella mongolica L. Papp, 2016

Pseudocollinella (Setiopacifrons) L. Papp, 2016

676. Pseudocollinella (Spinotarsella) pseudohumida

L. Papp, 2016

677. Pseudocollinella (Setiopacifrons) congoana L. Papp, 2016

678. Pseudocollinella (Setiopacifrons) normalis L. Papp, 2016

679. Pseudocollinella (Setiopacifrons) prima L. Papp, 2016

680. Pseudocollinella (Setiopacifrons) setisternalis L. Papp, 2016

681. Pseudocollinella (Setiopacifrons) vulnerata L. Papp, 2016

682. Pseudocollinella (Setiopacifrons) communis L. Papp, 2016

683. Pseudocollinella (Setiopacifrons) formosensis L. Papp, 2016

684. Pseudocollinella (Setiopacifrons) japonica L. Papp, 2016
685. Pseudocollinella (Setiopacifrons) koreana L. Papp, 2016

686. Pseudocollinella (Setiopacifrons) paradupliciseta L. Papp, 2016

687. Pseudocollinella (Setiopacifrons) pilitibia L. Papp, 2016

688. Pseudocollinella (Setiopacifrons) setipuga L. Papp, 2016

689. Pseudocollinella (Setiopacifrons) simplicisternum L. Papp, 2016

690. Pseudocollinella (Setiopacifrons) tercia L. Papp, 2016

691. Pseudocollinella (Setiopacifrons) trifida L. Papp, 2016

692. Pseudocollinella (Setiopacifrons) vietnamensis L. Papp, 2016

693. Cerodontha (Xenophytomyza) leptophallus L. Papp, 2016

694. Lygistorrhina austroafricana Blagoderov, Papp \& Hippa, 2013

695. Achaetothorax mahunkaorum L. Papp, 2017

696. Norrbomia paragravis L. Papp, 2017

697. Ceropterella mirifica L. Papp, 2017

698. Elachisoma simillimum L. Papp, 2017

699. Gonitella inornata L. Papp, 2017

700. Gonitella structuralis L. Papp, 2017

701. Minilimosina (Minilimosina) selecta L. Papp, 2017

702. Minilimosina (Svarciella) rohaceki L. Papp, 2017

703. Nudopella marshalli L. Papp, 2017

704. Nudopella erratica L. Papp, 2017

705. Nudopella pseudoperta L. Papp, 2017

706. Paraminilimosina similis L. Papp, 2017

707. Parapoecilosomella formosa L. Papp, 2017

708. Philocoprella africana L. Papp, 2017

709. Phthitia incognita L. Papp, 2017

710. Phthitia (Kimosina) vulgaris L. Papp, 2017

711. Piliterga africana L. Papp, 2017

712. Setositibiella secunda L. Papp, 2017

713. Spelobia foldvarii L. Papp, 2017

714. Terrilimosina improvisa L. Papp, 2017

715. Liriomyza acrostichalis L. Papp, 2017 
716. Liriomyza kerteszi L. Papp, 2017

717. Liriomyza michaeli L. Papp, 2017

718. Liriomyza parapuella L. Papp, 2017

719. Liriomyza rotundiphallus L. Papp, 2017

720. Liriomyza setistylus L. Papp, 2017

721. Myodris haennii Papp \& Pollini, 2021

722. Agromyza albinervis L. Papp, 2019

723. Agromyza carinata L. Papp, 2019

724. Agromyza deficiens L. Papp, 2019

725. Agromyza major L. Papp, 2019

726. Amauromyza (Cephalomyza) paragyrans L. Papp, 2019

727. Napomyza pusztae L. Papp, 2019

728. Phytomyza additionalis L. Papp, 2019

729. Phytomyza agnata L. Papp, 2019

730. Phytomyza argentata L. Papp, 2019

731. Phytomyza bukkensis L. Papp, 2019

732. Phytomyza filiformis L. Papp, 2019

733. Phytomyza hypophallus L. Papp, 2019

734. Phytomyza hypospinosa L. Papp, 2019

735. Phytomyza oligochaeta L. Papp, 2019
736. Phytomyza paracognata L. Papp, 2019

737. Phytomyza paratroliivora L. Papp, 2019

738. Phytomyza stenoptera L. Papp, 2019

739. Macrocera bipolaris L. Papp, 2021

740. Macrocera digitata L. Papp, 2021

741. Macrocera dubia L. Papp, 2021

742. Macrocera mixta L. Papp, 2021

743. Apterobiroina flavipes L. Papp, (in litteris)

744. Apterobiroina truncata L. Papp, (in litteris)

745. Bentrovata flavithorax L. Papp, (in litteris)

746. Bentrovata minor L. Papp, (in litteris)

747. Bentrovata nigrithorax L. Papp \& Szappanos, (in litteris)

748. Madiza dravensis L. Papp, (in litteris)

749. Phyllomyza botulipalpis L. Papp, (in litteris)

750. Phyllomyza irinae L. Papp, (in litteris)

751. Phyllomyza kiskunsagiensis L. Papp, (in litteris)

\title{
László Papp's journey (1946-2021): this is all he used to be once
}

\author{
BÉLA DaRVAS \\ Hungarian Society of Ecotoxicology, H-1022 Budapest, Herman Ottó út 15, Hungary \\ E-mail:bdarvas@bdarvas.hu
}

Summary - At the end of 1971, when László Papp started his scientific career, the Diptera Collection of the Hungarian Natural History Museum contained 330,000 specimens. In 2010, at the time of his retirement, that number reached one million. He considered the construction of the collection to be the most valuable part of his activities. In his scientific works, he established five family group names and 97 genus-group names and described 742 dipteran species new for science (additional nine will appear posthumously). He added more than 2,000 species of the dipteran fauna of Hungary. His articles were published mostly in Hungary, but in English. According to the 
Hungarian Scientific Database, it has received more than 2,500 independent citations so far for writing over 400. With five figures and two appendices: (1) publication list of László Pap selected by Béla Darvas and (2) list of family-, genus- and species-group names established by László Papp

Keywords - Diptera, Hungarian Academy of Sciences, Hungarian Natural History Museum, Manual of Palaearctic Diptera, taxonomy

\section{FIGURE CAPTIONS}

Figure 1. László Papp in 1973 (owned by the Papp family, source:

http://www.bdarvas.hu/portre/idn3503)

Figure 2. Outline of László Papp's professional life. 2: the stages of the progression - Ferenc Mihályi is the curator's predecessor of the Diptera Collection, V - teacher at Vecsési Primary School, ÁOE - university lecturer in the University of Veterinary Sciences, Department of General Zoology and Parasitology (head of department: Tibor Kassai), with bright yellow László Papp’s curatorial mandate; 3-13 significant working relationships in Hungary; tags: $C S c, D S c$, correspondent of the Hungarian Academy of Sciences, regular member of the Hungarian Academy of Sciences degree and ranks, the Széchenyi prize of the Hungarian Academy of Sciences, the beginning of the retiree status. (edited by Béla Darvas)

Figure 3. László Papp at his working desk in the Diptera-collection of the Hungarian Natural History Museum, in 2003. (photo: Béla Darvas, source: http://www.bdarvas.hu/portre/idn3503)

Figure 4. Analysis of László Papp's publications, based on the records of the Hungarian Library of Scientific Works and notes of László Papp: materials written for scientific qualification, books in English, books in Hungarian, books edited in English, articles in English, articles in Hungarian (list sorted and edited by Béla Darvas)

Figure 5. László Papp és and his cardiologist brother Lajos Papp around the 1970ies. (photo: owned by the Papp family, source: http://bdarvas.hu/main.php?id=6116) 